\title{
Hydraulic performance of
} fish guidance structures with curved bars - Part 1: head loss assessment

\section{Journal Article}

Author(s):

Beck, Claudia (1); Albayrak, Ismail (1); Meister, Julian (1); Boes, Robert (1)

Publication date:

2020

Permanent link:

https://doi.org/10.3929/ethz-b-000384896

Rights / license:

Creative Commons Attribution-NonCommercial 4.0 International

Originally published in:

Journal of Hydraulic Research 58(5), https://doi.org/10.1080/00221686.2019.1671515

Funding acknowledgement:

727830 - Fishfriendly Innovative Technologies for Hydropower (SBFI) 


\section{Hydraulic performance of fish guidance structures with curved bars - Part 1: Head loss assessment}

Claudia Beck, Ismail Albayrak, Julian Meister, Robert M. Boes

"This is an Accepted Manuscript of an article published by Taylor \& Francis in Journal of Hydraulic Research on 02.12.2019, available online:

https://www.tandfonline.com/doi/full/10.1080/00221686.2019.1671515

To cite this version:

Beck, C., Albayrak, I., Meister, J., Boes R.M. (2020). Hydraulic performance of fish guidance structures with curved bars: Part 1: Head loss assessment. Journal of Hydraulic Research, 58(5), 807-818, https://doi.org/10.1080/00221686.2019.1671515.

"This is an Accepted Manuscript version of the following article, accepted for publication in Journal of Hydraulic Research. Beck, C., Albayrak, I., Meister, J., Boes R.M. (2020). Hydraulic performance of fish guidance structures with curved bars: Part 1: Head loss assessment. Journal of Hydraulic Research, 58(5), 807-818, https://doi.org/10.1080/00221686.2019.1671515. It is deposited under the terms of the Creative Commons Attribution-NonCommercial License (http://creativecommons.org/licenses/by-nc/4.0/), which permits non-commercial re-use, distribution, and reproduction in any medium, provided the original work is properly cited." 
Hydraulic performance of fish guidance structures with curved bars - Part 1:

Head loss assessment

CLAUDIA BECK, MSc. Environmental Engineer, PhD Student, Laboratory of Hydraulics, Hydrology and Glaciology (VAW), ETH Zurich, Zürich, Switzerland

Email: beck@vaw.baug.ethz.ch (author for correspondence)

ISMAIL ALBAYRAK (IAHR Member), Dr., Research Scientist, Laboratory of Hydraulics, Hydrology and Glaciology (VAW), ETH Zurich, Zürich, Switzerland

Email: albayrak@vaw.baug.ethz.ch

JULIAN MEISTER, MSc. Environmental Engineer, PhD Student, Laboratory of Hydraulics, Hydrology and Glaciology (VAW), ETH Zurich, Zürich, Switzerland

Email: meister@vaw.baug.ethz.ch

ROBERT M. BOES (IAHR Member), Prof. Dr., Director, Laboratory of Hydraulics, Hydrology and Glaciology (VAW), ETH Zurich, Zürich, Switzerland

Email:boes@vaw.baug.ethz.ch

Running Head: Hydraulic performance of curved-bar racks for fish guidance 


\title{
Hydraulic performance of fish guidance structures with curved bars - Part 1: Head loss assessment
}

\begin{abstract}
The hydraulic performance of fish guidance structures such as louvres and angled bar racks is an important design criterion to achieve high fish guidance efficiencies with a minimum impact on hydropower production. The current geometrical designs of such structures result in high head losses and asymmetric turbine admission flow and hence need to be optimized. We therefore developed an innovative curved bar design for fish guidance structures and experimentally investigated different rack configurations in a laboratory flume. The present paper (Part I) focuses on the hydraulic performance of the novel curved-bar racks with regard to head losses, while in the companion paper (Part II) we report the results on the flow fields. The effects of the main rack angle, bar angle, bar spacing, bar depth, and top or/and bottom overlays were systematically studied. The curved bar shape leads to significantly lower head losses compared to straight bar shapes. An existing head loss prediction formula was extended to account for the new bar shape and the application of overlays.
\end{abstract}

Keywords: curved-bar rack; downstream fish migration; fish guidance; fish protection; head loss; louvre

\section{Introduction}

Switzerland has scheduled a gradual nuclear phase-out in a strategic plan for the future use of energy. As a consequence, clean and sustainable hydropower gains importance and its current share of nearly $60 \%$ in the Swiss energy market will likely increase. However, run-of-river HydroPower Plants (HPPs) disrupt fish migration routes resulting in decimating fish populations in river systems worldwide (Larinier \& Tavade, 2002; Courret \& Larinier, 2008). For an efficient restoration of water bodies, the European Water Framework Directive was enacted in 2000 and the revised Swiss Water Protection Act and Water Protection Ordinance was introduced in 2011. Both engineers and HPP operators therefore face the challenge of restoring the river continuum using fish protection and guidance systems at existing or new HPPs while maintaining the sustainable usage of hydropower. Fish Guidance Structures (FGS) with vertical bars for run-of-river hydropower applications, namely louvres (louvers in American English) and angled bar racks with an adjacent bypass system have been successfully applied in the northern US with high guidance efficiencies for the local fish species (Bates \& Vinsonhaler, 1957; Schuler \& Larson 1975; Taft, Hofmann, Eisle \& Horst, 1976; Electric Power Research Institute [EPRI] \& Dominion Millstone Laboratories [DML], 2001; Amaral, Winchell, McMahon, \& Dixon, 2003). Various studies demonstrate that such FGSs cause large hydraulic head losses and asymmetric turbine admission flow (Bates \& Vinsonhaler, 1957; Raynal, 
Chatellier, Courret, Larinier, \& David, 2013; Kriewitz 2015; Albayrak, Kriewitz, Hager, \& Boes, 2017). These are decisive indicators for long-term production losses and turbine efficiency and are therefore of great concern for HPP operators. To address these issues, Bates \& Vinsonhaler (1957) recommended flow straightening vanes for louvres. Albayrak et al. (2017) developed a modified version of angled bar racks, so-called Modified Bar Racks (MBRs) and reported 4 times reduced head losses compared to louvres. Shepherd, Katopodis, \& Rajaratnam (2007) further investigated louvres consisting of bars with a curved cross section in plan-view. They reported improved upstream flow fields, i.e. reduced flow deflection for curved bars compared to straight bars. However, this study was limited to a small parameter range and gave no indication on the downstream flow field, head losses, and fish guidance efficiencies of curved-bar rack configurations. In the following, the current state of knowledge is presented with regard to head losses and hydraulic design criteria of FGSs.

The herein described FGSs are classified as mechanical behavioral fish protection barriers consisting of vertical bars mounted in a rack. The basic rack design parameters affecting the hydraulic performance are the rack angle to the flow direction $\alpha\left(15^{\circ} \div 45^{\circ}\right)$, bar angle to flow direction $\beta\left(45^{\circ} \div 90^{\circ}\right)$ and clear bar spacing $s(25 \div 100 \mathrm{~mm}$ ) (Amaral, 2003; Amaral et al. 2003; Raynal et al., 2013; Albayrak et al., 2017). The vertical bars are oriented with a bar angle of $\beta=90^{\circ}$ to the flow direction in louvres, while the bar angles are $\beta=90^{\circ}-\alpha$ and $\beta \neq 90^{\circ}-\alpha$ for angled bar racks and MBRs, respectively (Fig. 1a). In contrast to conventional trash racks protecting intakes from large debris, FGSs are typically placed in front of a power intake at an angle $\alpha$ in plan view (Fig. 1b). The vertical bars of all three described FGSs create turbulent zones and flow separations (EPRI \& DML, 2001; Kriewitz, 2015), which are perceived and avoided by approaching fish. The velocity component parallel to the rack guides the fish towards a bypass system. The strong hydraulic cues induced by these FGSs allow for a wider bar spacing (Amaral, 2003).

Hydraulic head losses of conventional trash racks were first addressed by Kirschmer (1926). The head loss equation proposed was thereafter refined by e.g. Zimmermann (1969); Meusburger (2002); Clark, Tsikata, \& Haresign (2010). Meusburger (2002) additionally studied top, bottom, right, left and corner overlays attached to trash racks modelling different clogging patterns. Overlays might be also important components for FGSs since they can be used to guide drift wood, organic fine material and sediment to the bypass. Furthermore, several studies highlight that top and bottom overlays on FGSs could increase the guidance efficiency for surface and bottom oriented fish, respectively (Amaral et al., 2003; Boes \& Albayrak, 2017). However, to the authors' knowledge, no study is available on the effect of overlays on the hydraulic head losses of FGSs. 
Raynal et al. (2013) investigated the hydraulic head losses of angled bar racks with small bar spacings for fish guidance and established a head loss prediction formula for these structures. Albayrak et al. (2017) extended this study by including louvres and MBRs for a wide range of parameters. They developed a new formula based on the functional relations between the main parameters: rack angle $\alpha$, bar angle $\beta$, and clear bar spacing $s$ as well as the secondary parameters: bar depth $d$, bar shape $K$, and submergence depth $h_{s}$ (Fig. 1c and 1d). Although Albayrak et al. (2017) reported 4 times lower head losses for MBRs compared to louvres with $\alpha$ $=15^{\circ}$, head losses are still relatively high compared to conventional trash racks (Meusburger, 2002).

To fill the research gaps described above, we develop innovative curved-bar shapes (termed 'Curved-Bar Racks (CBR)' hereafter) for FGSs and systematically investigate their hydraulic performance in a laboratory flume aiming at the reduction of head losses and the improvement of the flow field up- and downstream of the rack. The present paper reports the results on the head losses while the companion paper (Part II) focuses on the flow field around the CBRs (Beck, Albayrak, Meister, \& Boes, 2019). The goals of the present study include (i) individual and combined effects of different rack and bar shape parameters, (ii) the effects of top, top \& bottom and bottom overlays, (iii) extension of the existing head loss prediction formula and (iv) recommendations for engineering applications.

\section{Experimentation}

\subsection{Test set-up}

Head loss measurements were conducted in a $0.6 \mathrm{~m}$ deep, $1 \mathrm{~m}$ wide and $12.0 \mathrm{~m}$ long flume with a horizontal bottom and a maximum discharge of $Q=120 \mathrm{l} \mathrm{s}^{-1}$. The flume width of $1.0 \mathrm{~m}$ was reduced to $w_{c h}=0.5 \mathrm{~m}$ using prefabricated PVC wall elements to study 1:2 Froude-scaled model racks (Fig 2, Table 1). Due to the limited capacity of the pump, the flume width reduction was necessary in order to reach flow conditions comparable to prototype conditions. The $7.0 \mathrm{~m}$ long test section where the measurements were conducted is equipped with a glass wall for lateral observation. The 1:2 Froude-scaled model CBRs were placed in the centre of the test section. The setup did not include a bypass. At the channel inlet, a stilling tank with an adjacent honeycomb flow straightener and a $45^{\circ}$ sloped ramp ensured symmetrical inflow conditions. The inflow depth $h_{o}$ was controlled with a flap gate at the end of the flume. The discharge was measured with a magnetic inductive discharge-meter of $\pm 0.5 \%$ accuracy. A $2 \mathrm{D}$ traverse system was mounted on top of the model flume over the entire length of the test section. The system allowed for the measuring devices to reach every point in the streamwise and spanwise directions. The coordinates in the streamwise, spanwise and vertical directions are $x, y$ and $z$, 
respectively. An ultrasonic distance sensor of $\pm 0.5 \mathrm{~mm}$ accuracy and a down-looking Acoustic Doppler Velocimetry probe (ADV; Sontek) were mounted on the traverse system. The origin of the coordinate system was $0.5 \mathrm{~m}$ downstream of the test section inlet as indicated in Fig 2 .

\subsection{Experimental procedure}

For the hydraulic head loss assessment, the average up- and downstream flow depths $h_{o}$ and $h_{2}$ were determined from three individual measurements $0.05 \mathrm{~m}$ away from each flume wall and in the centre axis in the spanwise direction at $x=0 \mathrm{~m}$ and $x=6 \mathrm{~m}$, respectively (cf. Fig. 2). The inflow water and time-averaged velocity were $h_{o} \approx 0.4 \mathrm{~m}$ and $U_{o} \approx 0.5 \mathrm{~m}$ for all experiments. The rack (subscript $R$ ) head losses $\Delta h_{R}$ in the horizontal flume were determined by applying Bernoulli's equation

$$
h_{o}+\frac{U_{o}^{2}}{2 g}=h_{2}+\frac{U_{2}^{2}}{2 g}+\Delta h_{R}+\Delta h_{f} .
$$

Here $g=9.81 \mathrm{~m} \mathrm{~s}^{-2}$ is the gravity acceleration and $\Delta h_{f} \cong 1.8 \mathrm{~mm}$ is the head loss due to flume friction measured without a rack. The rack head loss coefficient $\xi_{R}$ was determined from

$$
\xi_{R}=\Delta h_{R}\left(\frac{2 g}{U_{o}^{2}}\right)
$$

\subsection{Parameter range and test programme}

The main parameters representing the geometric characteristics of the CBR are: $\alpha, \beta$, and $s$, while the secondary parameters are: bar depth $d$, bar shape $K$, and bottom and top overlay height $h_{B o}$ and $h_{T o}$, respectively (Fig. 3). The height of the top \& bottom overlay combination is denoted $h_{v}$. Two types of curved bars were furnished from $45^{\circ}$ and $90^{\circ}$ circle segments of an acrylic pipe. Both bar types have an outflow angle of $\delta=0^{\circ}$ parallel to the downstream channel walls (Fig. $3 \mathrm{a} / \mathrm{b})$. The bars differ from each other with an angle of attack $\beta=45^{\circ}$ and $90^{\circ}$. These bar shapes are denoted by $K_{c, 45}$ and $K_{c, 90}$ and correspond to the streamlined version of the rounded rectangular bars $K_{r}$ of MBRs with $\beta=45^{\circ}$ and louvres with $\beta=90^{\circ}$, respectively (Albayrak et al., 2017). The curved bars have a thickness $t=0.01 \mathrm{~m}$, a standard bar depth $d=0.1 \mathrm{~m}$ (prototype dimensions) and are rounded at both ends with a radius $r=t / 2$. The investigated CBRs were horizontally angled to the flow with $\alpha=15^{\circ}, 30^{\circ}$, and $45^{\circ}$. The hydraulic parameters relevant for the head loss assessment are the flume width $w_{c h}$, the up- and downstream flow depths $h_{o}$ and $h_{2}$, and the depth-averaged up- and downstream flow velocities $U_{o}=Q /\left(h_{o} \cdot w_{c h}\right)$ and $U_{2}=Q /\left(h_{2} \cdot w_{c h}\right)$, respectively. 
Head losses were determined for the entire range of primary and secondary parameters. Overall, the present head loss assessment of CBRs is based on 378 single experiments. The experimental matrix is shown in Table 1 for both model and prototype dimensions. The bar depth effect was only tested for $\alpha=30^{\circ}$ and $45^{\circ}$ with $d=0.035,0.05$ and $0.0625 \mathrm{~m}$. The effect of overlays was investigated for all rack configurations. Relative overlay heights of $h_{T o} / h_{o}, h_{B o} / h_{o} \cong 10,15$, $25 \%$ were tested for top and bottom overlays separately. For the combination of top \& bottom overlays, $h_{v} / h_{o} \cong 20$ and $30 \%$ were considered corresponding to $10 \%$ and $15 \%$ for each top and bottom overlay, respectively. All rack configurations were tested at steady inflow conditions. The non-dimensional bar spacing is defined as $\sigma=t /(t+s)$. Zero bar spacing results in $\sigma=1$, which is synonymous to full blockage. The non-dimensional bar depth is defined as $\mathcal{E}=d / D$, equal to $\varepsilon=0.70,1.00$ and 1.25 with $D=0.10 \mathrm{~m}$ at prototype scale as the reference bar depth. The bars were fully submerged over the entire flow depth in all experiments. The blockage ratio of overlay elements $V_{i}=h_{v, i} / h_{o, i}$ is the ratio of the area of the total overlay area $A_{o v, i}=h_{v, i}$. $w_{c h} / \sin \alpha$ to the total rack area $A_{R}=h_{o, i} \cdot w_{c h} / \sin \alpha$.

\subsection{Scale effects}

To avoid significant scale effects, all experiments reported hereafter were conducted with upstream flow depth to bar thickness ratio $h_{o} / t \cong 80$, bar Reynolds numbers $\mathrm{R}_{b}=t \cdot U_{o} / v \cong$ 2,500 with $v=1.01 \cdot 10^{-6}$ for $20^{\circ} \mathrm{C}$, approach flow Reynolds number $\mathrm{R}=4 \cdot R_{h} \cdot U_{o} / v \cong 3.1 \cdot 10^{5}$ based on the hydraulic radius $R_{h}=h \cdot w_{c h} /\left(2 h+w_{c h}\right)$, and the approach flow Froude number $\mathrm{F}=$ $U_{o} /\left(g \cdot h_{o}\right)^{0.5} \cong 0.25$. These values are chosen based on our preliminary test results on scale effects and the findings by Zimmermann (1969), Meusburger (2002), Raynal et al. (2013) and Albayrak et al. (2017).

\section{Results}

\subsection{Rack head loss equation}

The rack head loss coefficient $\xi_{R}=\mathrm{f}\left(\alpha, \beta, \sigma, \varepsilon, K_{i}, V_{i}\right)$ is a non-dimensional parameter and a function of the above described rack, bar and overlay parameters. The rack angle $\alpha$, the bar angle $\beta$ and the non-dimensional axial bar distance $\sigma$ characterize the basic geometric rack properties. According to Albayrak et al. (2017), the basic (subscript $B$ ) rack head loss coefficient $\xi_{B}=\mathrm{f}(\alpha, \beta$, $\sigma$ ) is a function of these parameters. The head loss factors $C_{S}, C_{L}$ and $\mathrm{C}_{V, i}$ describe the effects of the secondary parameters: bar shape, bar depth or additional overlays, respectively. Overall, the rack head loss coefficient $\xi_{R}$ is a product of the basic head loss coefficient and the head loss factors: 
$\xi_{R}=\xi_{B} \cdot C_{S} \cdot C_{L} \cdot C_{V, i}$

Figure 4 shows the experimentally obtained $\xi_{R}$ values for CBRs versus the main rack parameters $(\alpha, \beta, \sigma)$. Three fundamental correlations are observed: (I) Reducing the bar spacing $s$ and hence increasing $\sigma$ leads to higher rack blockage and thus to higher $\xi_{R}$ values (Fig. $4 \mathrm{a}$ ). This effect is small for $\beta=45^{\circ}$ compared to $\beta=90^{\circ}$; (II) decreasing $\beta=90^{\circ}$ to $45^{\circ}$ leads to a less pronounced flow deflection and hence $\xi_{R}$ is decreased (Fig. $4 \mathrm{~b}$ ). The flow straightening effect of curved bars is stronger for lower $\beta$ values causing a smaller recirculation zone downstream of the CBR (compare Fig 5a with 5b and see the companion paper (Part II) (Beck et al., 2019)). (III) Increasing $\alpha$ decreases the rack area and thus increases the flow velocity in front of the rack. This effect partly leads to higher $\xi_{R}$ with increasing rack angles $\alpha$. For $\sigma=0.04$, however, this trend is reversed because an increase of $\alpha$ creates gaps between the bars, reducing the rack resistance. Both effects are stronger for $\beta=90^{\circ}$ compared to $\beta=45^{\circ}$ (Fig. $4 \mathrm{c}$ ).

The above observed correlations are quasi-similar to those reported by Albayrak et al. (2017) for MBRs. Therefore, the rack head loss prediction equation is developed in the same form as proposed by Albayrak et al. (2017). The equation for the basic head loss coefficient developed by Albayrak et al. (2017) for MBRs with straight bars is taken as a basis since it is valid for the parameter range of the present study:

$$
\xi_{B}=245\left[0.0275+(\sigma-0.0815)\left(\frac{\alpha}{90^{\circ}}\right)\right] \cdot\left(\frac{\beta}{90^{\circ}}\right)^{5 \sigma^{0.44}}
$$

\section{Bar shape factor $C_{S}$}

The bar shape for straight bars is $C_{S, \text { straight }}=1$ (Albayrak et al., 2017). To determine the shape factor for curved bars, the predicted (subscript $p$ ) head loss coefficients $\xi_{R, p}$ using Eqs. (3) and (4) are compared with the measured (subscript $m$ ) CBR head loss coefficients $\xi_{R, m}$ for the main parameters (Fig. 4). Note that the bar depth is the standard bar depth $D=0.10 \mathrm{~m}$ at prototype scale $\left(C_{L}=1\right)$, no overlay is considered $\left(C_{V, i}=1\right)$ and hence Eq. (3) reduces to $\xi_{R}=\xi_{B} \cdot C_{S}$. The resulting ratios in Fig. 6 show that the $\xi_{R}$ values for CBRs are 2.6 to 5.5 times lower than those predicted for the equivalent MBR configurations with straight bars with an average of 4.2, a standard variation of 0.94 and a variance of 0.88 . Since no specific effects or trends of $\alpha, \beta$ or $\sigma$ on the ratios are identified, the average value of the ratios is considered to account for the overall effects of these parameters leading to a bar shape coefficient for CBRs of

$$
C_{S, \text { curved }}=\left(\frac{1}{4.2}\right) \approx 0.24 \text {. }
$$


This coefficient $C_{S \text {, curved }}=0.24$ indicates that $\xi_{R}$ values for curved bars are reduced by $76 \%$ on average as compared to straight bars for the investigated rack configurations. The coefficient of determination for the best fit of $\xi_{R}=\xi_{B} \cdot C_{S}$ is $R^{2}=0.95$.

\section{Head loss factor of bar depth $C_{L}$}

The effect of the bar depth $d$ on the head loss coefficient was investigated for $\alpha=30^{\circ}, 45^{\circ}, \beta=$ $45^{\circ}, 90^{\circ}$, and $\sigma=0.04,0.08,0.17$. For $\varepsilon=0.7$ and $1.25, C_{L}$ values were computed as the ratio of $\xi_{R}$ values for $\varepsilon=0.7$ or $\varepsilon=1.25$ to $\xi_{R}$ for $\varepsilon=1$, describing the head loss change from the standard bar depth to the shorter and longer bar depths, respectively. The curve fit analysis gives

$C_{L}=\left[1+3.3(1-\varepsilon)\left(\frac{\alpha}{90^{\circ}}\right)\right] \sigma^{2(1-\varepsilon)\left(\frac{\alpha}{90^{\circ}}\right)}, \quad R^{2}=0.75$

provided that $45^{\circ} \leq \beta \leq 90^{\circ}, 30^{\circ} \leq \alpha \leq 45^{\circ}, 0.7 \leq \varepsilon \leq 1.25$, and $0.04 \leq \sigma \leq 0.17$. Eq. (6) satisfies the following boundary conditions: $\varepsilon=1 \rightarrow C_{L}=1$ and $\varepsilon=\infty \rightarrow C_{L}=\infty$. The application of Eq. (6) to CBRs with $\alpha=15^{\circ}$ is only approximate because the effect of bar depth $d$ on $\xi_{R}$ was only determined for $\alpha=30^{\circ}$ and $45^{\circ}$.

Figure 7 shows the curve fits of $C_{L}$ (Eq. 6) and the corresponding experimental data versus $\sigma$. For $\varepsilon=1, C_{L}$ is equal to unity. The effect of $\varepsilon$ on $\xi_{R}$ is the most pronounced for low $\sigma$, i.e. larger bar spacings, because the bars act as a single body in the flow, and the flow through the gaps between the bars in flow direction occurs as for isolated bars. Decreasing the bar depth from $\varepsilon=$ 1.25 to $\varepsilon=0.7$ reduces the projected bar area and hence the bar resistance. Therefore, the head loss coefficient $\xi_{R}$ decreases with decreasing $\varepsilon$. This trend diminishes with increasing $\sigma$ since the gaps between the bars are reduced and the bars even overlap in flow direction, resulting in increased bar resistance compared to the single bar. Despite the larger projected area, longer bars enhance the flow straightening effect of curved bars resulting in reduced $\xi_{R}$ and $C_{L}$ values below 1 at $\sigma=0.17$. For both rack angles $\alpha, C_{L}$ values follow a power-law function with $\sigma$.

For $\beta=90^{\circ}$ at $\sigma=0.17$, the data do not follow the trends explained above, and both shorter and longer bars strongly reduce $\xi_{R}$ and hence $C_{L}$ compared to the standard bar depth (Fig. 7b). Therefore, the data point marked with a grey circle in Fig. $7 \mathrm{~b}$ was considered as an outlier and excluded from the fit. Except for this behaviour at $\sigma=0.17$ and some data scatter for the other two $\sigma$ values, the effect of $\beta$ on $C_{L}$ is considered to be negligible within $45^{\circ} \leq \beta \leq 90^{\circ}$.

\section{Head loss factor of overlays $C_{V, i}$}

Different blockage ratios of top, top \& bottom, and bottom overlays, $V_{1}, V_{2}$ and $V_{3}$, were investigated for all CBR configurations listed in Table 1 . The $C_{V, i}$ values were computed by 
dividing the measured $\xi_{R, m}$ values of overlay configurations with the $\xi_{R, m}$ values of corresponding no-overlay configurations. An overlay factor $K_{V, i}$ is introduced with the boundary conditions $K_{V, i}=0 \rightarrow C_{V, i}=1$ and $K_{V, i}=\infty \rightarrow C_{V, i}=\infty$ as

$$
C_{V, i}=1+K_{V, i}
$$

Figure 8 shows $C_{V, i}$ versus $V_{i}$ for $\alpha=15^{\circ}, 30^{\circ}$ and $45^{\circ}, \beta=90^{\circ}, \sigma=0.04,0.08$ and $0.17, \varepsilon=1$ and top, top \& bottom and bottom overlays. The experimental data reveal a different effect of individual top $\left(C_{V, 1}\right)$ and bottom $\left(C_{V, 3}\right)$ overlays on the head loss compared to the combination of top \& bottom overlays $\left(C_{V, 2}\right)$. The $C_{V, 1}$ and $C_{V, 3}$ values match well and are larger than $C_{V, 2}$ values at the same $\sigma$ values for a given overlay blockage ratio $V_{i}$. This trend is independent of the rack angle $\alpha$. For all overlay configurations, all $C_{V, 1}, C_{V, 2}$ and $C_{V, 3}$ values are highest for large bar spacings $(\sigma=0.04)$ and lowest for smaller bar spacings $(\sigma=0.17)$. This result is expected because the additional blockage by overlays leads to a sharp increase of the total rack blockage for $\sigma=0.04$ compared to $\sigma=0.17$ where the blockage due to the bars is already the highest.

The rack angle $\alpha$ has a significant effect on $C_{V, i}$. The $C_{V, i}$ values increase with increasing overlay blockage ratio $V_{i}$ for $\alpha=45^{\circ}$ whereas the trend is opposite for $\alpha=15^{\circ}$. This result is attributed to the facts that: (I) decreasing $\alpha$ results in lower velocities at the rack and hence lower rack resistance, and (II) the overlays distribute the flow more uniformly along the rack resulting in lower $C_{V, i}$ values.

Since $C_{V, i}$ and hence $K_{V, i}$ depend on the overlay positions at the rack, a separate curve-fit analysis with $K_{V, i}=\mathrm{f}\left(\alpha, \beta, \sigma, V_{i}\right)$ was made. The experimental data follow the fits

$$
\begin{aligned}
& K_{V, 1,3}=\left[10\left(\frac{90^{\circ}}{\beta}\right)\left(\frac{V_{i}}{1-V_{i}}\right)^{4.3 \sigma^{0.75}\left(\frac{\alpha}{90^{\circ}}\right)}\right]-5.3\left(\frac{V_{i}}{1-V_{i}}\right)^{1.7}, \text { top or bottom overlay } \\
& K_{V, 2}=\left[7\left(\frac{90^{\circ}}{\beta}\right)\left(\frac{V_{i}}{1-V_{i}}\right)^{\left.9.5 \sigma^{1.2\left(\frac{\alpha}{90^{\circ}}\right)}\right]-1.5\left(\frac{V_{i}}{1-V_{i}}\right)^{1.4}, \text { top \& bottom overlay }}\right.
\end{aligned}
$$

provided that $0 \leq V_{i} \leq 0.30$. Eqs. (8) and (9) satisfy the following boundary conditions: $V_{i}=0 \rightarrow$ $K_{V, i}=0$ and $V_{i}=1 \rightarrow K_{V, i}=\infty$.

Figure 9 shows the factor $K_{V, 1}$, i.e. top overlay, versus $V_{1} /\left(1-V_{1}\right)$ and the corresponding powerlaw function for $\alpha=15^{\circ}, 30^{\circ}, 45^{\circ}, \beta=45^{\circ}, 90^{\circ}, \sigma=0.04,0.08,0.17$, and $\varepsilon=1$. These configurations are selected as examples to compare the predicted $K_{V, i}$ values using Eqs. (7) and (8) with the experimental data. In general, the predicted $K_{V, I}$ match well with the measured $K_{V, I}$ 
values. Figure 9 also shows the effect of $\beta$ on $K_{V, 1}$. The $K_{V, 1}$ values are generally higher for $\beta=$ $45^{\circ}$ than those for $\beta=90^{\circ}$. Since the $\xi_{B}$ values are relatively small for $\beta=45^{\circ}$ compared to $\beta=$ $90^{\circ}$, additional blockage by overlays has a stronger effect for $\beta=45^{\circ}$.

\subsection{Application of total head loss formula}

Figure 10a shows the measured head loss coefficients $\xi_{R, m}$ versus the corresponding predicted values $\xi_{R, p}$ using Eq. (3). The data include all rack configurations (see Table 1). Note that this validation is based on the data which were used to derive the equation, thus no independent data were used. The predicted values, $\xi_{R, p}$, are in good accordance with the measured values, $\xi_{R, m}$. The coefficient of determination for the best fit is $R^{2}=0.93$.

The head loss estimate based on Eq. (3) includes errors associated with the accuracy of instruments as well as assumptions made in the data analysis (see section 3.1). Therefore, to apply Eq. (3), a Prediction Error PE $=\left(\xi_{R, p}-\xi_{R, m}\right) / \xi_{R, m} \cdot 100$ of $\pm 50 \%, 30 \%$ and $15 \%$ should be accounted for head loss coefficients $\xi_{R, p}<2.5,2.5 \leq \xi_{R, p}<4$ and $\xi_{R, p} \geq 4$, respectively (Fig. $10 b)$.

\section{Discussion}

\subsection{Comparison with literature data}

The head loss prediction formula proposed by Albayrak et al. (2017) for louvres, angled bar racks and MBRs is extended with the shape factor $C_{S}$ and the bar depth factor $C_{L}$ for curved-bar racks, i.e. CBRs, and the overlay blockage factor $C_{V, i}$. Since the two studies were conducted in the same flume for a similar parameter range, their range of application is comparable.

Similar flow-rack-interactions for CBRs and MBRs lead to analogous effects of basic parameters on $\xi_{B}$ and to the application of Eq. (4) for both FGS types. However, different equations are suggested to account for the bar shape and depth effects. In the equation proposed by Albayrak et al. (2017), $C_{L}$ increases linearly with increasing $\sigma$ and decreasing $\alpha$ for louvres. The effect of $C_{L}$ on MBRs was not investigated.

The research of the overlay effect on the head losses of FGSs is limited. Boes and Albayrak (2017) investigated the effect of an $11 \%$ bottom overlay on the head losses for three different louvre and MBR configurations with a bypass. They found that this overlay decreases the head loss for the louvre $\left(\alpha=15^{\circ}, \beta=90^{\circ}\right)$ but increases the head losses for MBRs $\left(\alpha=15^{\circ}\right.$ and $30^{\circ}, \beta$ $=45^{\circ}$ ), thus proposing the following relation:

$$
C_{V, 3}=0.82(\sin \beta)^{-0.8}
$$


with the additional boundary condition that $C_{V, 3}=1$ if no bottom overlay is installed. Since Boes and Albayrak (2017) did not study the effect of bar spacing $\sigma$ and various blockage ratios $V_{i}$ on $C_{V, i}$, the application of Eq. (10) is limited to the three FGS configurations investigated. Figs. 8 and 9 demonstrate that $\alpha, \beta, \sigma$, and $V_{i}$ are the decisive parameters for the overlay head loss prediction, which are not taken into account in Eq. (10). The maximum deviation between the measured $\xi_{R}$ (Boes \& Albayrak, 2017) and the $\xi_{R}$ calculated with Eq. (8) is $12 \%$ for MBRs and $16 \%$ for the louvre. These results indicate that the herein proposed Eqs. (8) and (9) also apply for both MBRs and louvres in addition to CBRs with overlays.

\subsection{Engineering application}

Hydraulic head losses of FGSs are affected by a large number of parameters. In this subsection, these parameters are analysed for an adequate engineering design with regard to the hydraulic performance, efficient fish guidance as well as operational and economic issues. As shown in subsection 3.1, the impacts of primary parameters $\alpha, \beta$ and $\sigma$ on $\xi_{R}$ are similar for both CBRs and MBRs described by Albayrak et al. (2017). Among the three parameters, the bar angle $\beta$ has the most significant impact on $\xi_{R}$. For $\sigma=0.17, \xi_{R}$ decreases about six times from $\beta=90^{\circ}$ to $\beta=45^{\circ}$ (Fig. 4b). The authors therefore recommend CBRs with $\beta=45^{\circ}$ over those with $\beta=90^{\circ}$.

The second most influencing factor on $\xi_{R}$ is the bar spacing $\sigma$. For $\beta=45^{\circ}$, however, the effect of $\sigma$ is relatively small (Fig. 4a) and therefore, the bar spacing should be selected mainly based on the size of the target fish species. To ensure a high degree of fish guidance, the dimensionless bar spacing of $\sigma=0.17$ is recommended. In the present study, this corresponds to a $0.05 \mathrm{~m}$ clear bar spacing and a $0.01 \mathrm{~m}$ bar thickness at prototype scale.

Although $\alpha$ has the least impact on $\xi_{R}$, it strongly affects other parameters. Based on Fig. 8, $\alpha$ should not be larger than $45^{\circ}$, since the application of overlays significantly increases $\xi_{R}$. Furthermore, $\alpha$ should not be smaller than $15^{\circ}$ due to the high cost of excessive structural length. Considering these issues, the optimum value of $\alpha$ around $30^{\circ}$ is recommended.

If structural rigidity and large wood and sediment accumulations are no issues, a shorter relative bar depth of $\varepsilon=0.70$ is recommended due to reduced head losses and cost compared to $\varepsilon=1.0$. Otherwise the bar depth has to be increased accordingly.

The effect of a top and/or bottom overlay on $\xi_{R}$ strongly depends on the basic parameters $\alpha, \beta$, and $\sigma$. If $\sigma=0.17$, additional overlay blockage has only a small effect on $\xi_{R}$. Ebel (2016) proposes a minimum height for top and bottom overlay of $1.0 \mathrm{~m}$ and $0.5 \mathrm{~m}$, respectively. Based on the results of our experiments, we recommend $h_{v}=0.20 \div 0.30 h_{o}$ for a high fish guidance efficiency and the mitigation of operational issues by considering site-specific geometrical and operational conditions. 
In Figure 11a, the hydraulic head losses of CBRs are compared with other FGS types and conventional trash racks. The $\xi_{R}$ values of CBRs and MBRs with $\alpha=30^{\circ}$ and $\beta=45^{\circ}$ were calculated with Eq. (3) in combination with Eq. (5) or $C_{s}=1$, respectively. The $\xi_{R}$ values of Horizontal Bar Racks (HBR) with $\alpha=30^{\circ}$ and of conventional trash racks placed perpendicular to the approach flow were computed with the equations proposed by Albayrak, Maager, \& Boes (2019) and Meusburger (2002), respectively. In Figure 11a, all equations were used in their respective limitations and rack and hydraulic configurations. Increasing $\sigma$ results in increasing $\xi_{R}$ for conventional trash racks and all FGSs. Dimensionless bar spacings between $0.17 \leq \sigma \leq 0.33$ lie outside the limits of the FGS equations. The $\xi_{R}$ values of CBRs are significantly lower compared to MBRs. Furthermore, they are in the range of $\xi_{R}$ values of conventional trash racks used at Swiss run-of-river HPPs (Meusburger, 2002) and of HBRs.

The recommended MBR (Albayrak et al., 2017), HBR (Albayrak et al., 2019), and CBR configurations are compared in Fig. 11b. As shown in Fig. 6, the use of the proposed curved bar shape for CBRs reduces the head losses significantly compared to the equivalent MBRs with straight bars. Currently, European practice guidelines recommend HBRs with $s=10 \div 20 \mathrm{~mm}$ to ensure high fish protection and guidance, particularly for small HPPs $\left(Q<100 \mathrm{~m}^{3} \mathrm{~s}^{-1}\right)$

(ONEMA, 2014; Ebel, 2016). With the demonstrated hydraulic performance and head losses in the range of HBRs, CBRs might be an alternative to HBRs for small HPPs with the advantage of mitigating common clogging problems of HBRs. Furthermore, the larger bar spacings reduce the construction cost of CBRs compared to HBRs, and the rack cleaning machine design becomes more standard as for conventional trash racks and therefore more economical. Further research assessing the velocity fields as well as biological parameters such as fish behaviour and guidance efficiency of CBRs is required and will be performed in the course of the present research project. The flow fields of selected CBR configurations are reported in the companion paper (Part II) completing the study on the hydraulic performance of CBRs for fish guidance. Research on operational issues such as the accumulation of large wood, organic fine material, and sediment during flood events and the application of conventional rack cleaning machines for CBRs are recommended.

\section{Conclusions}

In the present study, innovative curved bar designs for fish guidance structures were developed and investigated at 1:2 Froude-scaled detail models in a laboratory flume. Hydraulic head losses were experimentally determined for a range of rack configurations with curved bars. The existing head loss formula developed for fish guidance structures with straight bars was further extended to account for the novel curved bar shapes and overlays. The studied primary parameters are the rack angle, bar angle, and clear bar spacing characterizing the basic geometric 
properties of a curved-bar rack and the secondary parameters are bar shape, bar depth, and various overlay combinations. The present study comprises the following key findings:

1. Hydraulic head losses of curved-bar racks are on average 4.2 times lower as compared to the equivalent fish guidance structures with straight bars and are thus in the same range as for conventional trash racks used at many run-of-river hydropower plants.

2. The existing head loss formula developed for louvres and angled bar racks was extended with a constant shape factor of $1 / 4.2 \approx 0.24$ accounting for curved bars and an overlay factor for the application of top, top \& bottom, and bottom overlays.

3. Amongst the studied parameters, the bar angle has the most significant impact on the rack head losses, which decrease about six times if the bar angle is reduced from $90^{\circ}$ to $45^{\circ}$.

4. The recommended rack configuration has a rack angle of $30^{\circ}$, a bar angle of $45^{\circ}$ and a clear bar spacing of $5 \mathrm{~cm}$. The head loss coefficient for this configuration is 0.57 . With additional top and bottom overlays of $15 \%$ each the head loss coefficients increases to 0.76 .

Given the significantly reduced head losses, curved-bar racks present a high potential over louvres and modified bar racks with straight bars for fish protection and guidance facilities at hydropower plants, minimizing negative economic impacts.

\section{Acknowledgements}

This project has received funding from the European Union's Horizon 2020 research and innovation programme under grant agreement No. 727830, FITHydro (Fishfriendly Innovative Technologies for Hydropower). The authors would further like to thank the State Secretariat for Education, Research and Innovation (SERI) for their support. VAW's activities in hydropower research are embedded in the Swiss Competence Center for Energy Research, Supply of Electricity (SCCER-SoE), which is an initiative funded by the Swiss Confederation through Innosuisse (Swiss Innovation Agency).

\section{Abbreviations}

FGS fish guidance structure

HBR horizontal bar rack

HPP hydropower plant

MBR modified bar rack

CBR curved-bar rack

PE prediction error 


\section{Notation}

$A_{R}=$ wetted bar rack area $\left(\mathrm{m}^{2}\right)$

$A_{o v}=$ overlay area $\left(\mathrm{m}^{2}\right)$

$C_{L}=$ head loss factor of bar depth (-)

$C_{S}=$ head loss factor of bar shape (-)

$C_{V, i}=$ head loss factor of overlay blockage (-)

$\mathrm{F}=U_{o} /\left(g \cdot h_{o}\right)^{0.5}=$ Froude number $(-)$

$g=$ gravity acceleration $\left(\mathrm{m} \mathrm{s}^{-2}\right), \mathrm{g}=9.81 \mathrm{~m} \mathrm{~s}^{-2}$

$h=$ flow depth (m)

$h_{2}=$ downstream flow depth $(\mathrm{m})$

$h_{B o}=$ bottom overlay height $(\mathrm{m})$

$h_{o}=$ upstream flow depth (m)

$h_{s}=$ rack submergence depth $(\mathrm{m})$

$h_{T o}=$ Submerged top overlay height (m)

$h_{v}=$ total overlay height as a combination of top and bottom overlays $h_{T o}+h_{B o}(\mathrm{~m})$

$K_{i}=$ bar shape $(-)$

$K_{V, i}=$ overlay factor (-)

$d=$ bar depth $(\mathrm{m})$

$D=$ reference bar depth (m) (0.10 m herein)

$P=$ blockage ratio (-)

$Q=$ discharge $\left(\mathrm{m}^{3} \mathrm{~s}^{-1}\right)$

$\mathrm{R}=4 \cdot R_{h} \cdot U_{o} / v=$ Reynolds number based on hydraulic radius (-)

$\mathrm{R}_{b}=t \cdot U_{o} / v=$ bar Reynolds number (-)

$R_{h}=h \cdot w_{c h} /\left(2 h+w_{c h}\right)=$ hydraulic radius $(\mathrm{m})$

$s=$ clear spacing between bars $(\mathrm{m})$

$t=$ bar thickness (m)

$U_{2}=$ average downstream velocity $\left(\mathrm{m} \mathrm{s}^{-1}\right)$

$U_{o}=$ average upstream velocity $\left(\mathrm{m} \mathrm{s}^{-1}\right)$

$V_{1}, V_{2}, V_{3}=h_{v, i} / h_{o, i}=$ blockage ratio of top, top \& bottom, bottom overlay (-)

$w_{c h}=$ flume width (m)

$x, y, z=$ streamwise, spanwise and vertical directions $(\mathrm{m})$

$\alpha=$ rack angle to flow direction or from wall ( $\left(^{\circ}\right)$

$\beta=$ bar angle to flow direction $\left(^{\circ}\right)$

$\delta=$ bar angle to downstream or power channel $\left(^{\circ}\right)$

$\varepsilon=d / D=$ non-dimensional bar depth (-)

$\Delta h_{R}=$ rack head loss $(\mathrm{m})$ 
$\xi=$ head loss coefficient (-)

$\xi_{B}=$ basic head loss coefficient (-)

$\xi_{R}=$ rack head loss coefficient (-)

$\xi_{R, m}=$ measured rack head loss coefficient (-)

$\xi_{R, p}=$ predicted rack head loss coefficient (-)

$\sigma=t /(t+s)=$ non-dimensional axial distance between bars (-)

$v=$ kinematic viscosity $\left(\mathrm{m}^{2} \mathrm{~s}^{-1}\right), v=1.01 \cdot 10^{-6}$ at $20^{\circ} \mathrm{C}$

\section{References}

Albayrak, I., Maager, F., \& Boes, R. M. (2019). An experimental investigation on fish guidance structures with horizontal bars. Journal of Hydraulic Research, accepted for publication, DOI: 10.1080/00221686.2019.1625818.

Albayrak, I.; Kriewitz, R. C.; Hager, W. H.; Boes, R. M. (2017). An experimental investigation on louvres and angled bar racks. Journal of Hydraulic Research, 56(1): 59-75, DOI: 10.1080/00221686.2017.1289265.

Amaral, S. V. (2003). The use of angled bar racks and louvers for guiding fish at FERCLicensed Projects. FERC Fish Passage Workshop, Holden, USA.

Amaral, S. V., Winchell, F. C., McMahon, B. J., \& Dixon, D. (2003). Evaluation of angled bar racks and louvers for guiding silver phase American eels. Proc. Biology, Management and Protection of Catadromous Eels, 367-376, D.A. Dixon, ed. American Fisheries Society, Bethesda MD.

Bates, D. W., \& Vinsonhaler, R. (1957). Use of louvers for guiding fish. Transactions of the American Fisheries Society, 86(1), 38-57.

Beck, C., Albayrak, I., Meister, J., \& Boes, R. M. (2019). Hydraulic performance of fish guidance structures with curved bars - Part 2: Flow fields. Journal of Hydraulic Research

Boes R. M., \& Albayrak, I. (2017). Fish guidance structures: New head loss formula and fish guidance efficiencies. Proceedings of the $37^{\text {th }}$ IAHR World Congress. Kuala Lumpur, Malaysia, 2495-2501.

Clark, S. P., Tsikata, J. M., \& Haresign, M. (2010). Experimental study of energy loss through submerged trashracks. Journal of Hydraulic Research, 48(1), 113-118.

Courret, D., \& Larinier, M. (2008). Guide pour la conception de prises d'eau "ichtyocompatibles" pour les petites centrales hydroélectriques [Guide for the design of fishfriendly intakes for small hydropower plants]. France : Agence de L'Environnement et de la Maîtrise de l'Energie (ADEME). Retrieved from http://www.onema.fr/IMG/pdf/2008_027.pdf (in French). 
Ebel, G. (2016). Fischschutz und Fischabstieg an Wasserkraftanlagen - Handbuch Rechen- und Bypasssysteme. Ingenieurbiologische Grundlagen, Modellierung und Prognose, Bemessung und Gestaltung [Fish Protection and downstream fish migration at hydropower plants - Handbook for fish guidance and bypass systems]. $2^{\text {nd }}$ edn., Mitteilungen aus dem Büro für Gewässerökologie und Fischereibiologie, Band 4, (in German).

EPRI (Electric Power Research Institute) \& DML (Dominion Millstone Laboratories) (2001). Evaluation of angled bar racks and louvers for guiding fish at water intakes. Report 1005193: 106. Palo Alto, CA and Waterford, CT.

Kriewitz, C. R. (2015). Leitrechen an Fischabstiegsanlagen - Hydraulik und fischbiologische Effizienz [Guidance screens at fish protection facilities - Hydraulics and fish-biological efficiency]. VAW-Mitteilung 230, R. M. Boes, ed. Laboratory of Hydraulics, Hydrology and Glaciology (VAW), ETH Zurich, Zürich, Switzerland (in German).

Kirschmer, O. (1926). Untersuchungen über den Gefällsverlust an Rechen [Investigation on the hydraulic head losses of racks]. Mitteilungen des hydraulischen Instituts der TH München, Proc. Vol. 1., Germany (in German).

Larinier, M., \& Travade F. (2002). Downstream migration: Problems and facilities. Bulletin Français de la Pêche et de la Pisciculture, 364, 181-207

Meusburger, H. (2002). Energieverluste an Einlaufrechen von Flusskraftwerken [Head losses at intakes of run-of-river hydropower plants]. VAW-Mitteilung 179, H.-E. Minor, ed. Laboratory of Hydraulics, Hydrology and Glaciology (VAW), ETH Zurich, Zürich, Switzerland (in German).

ONEMA (2014). Assessing the passage of obstacles by fish - Concepts, design and application. Technical Report. The National Agency for Water and Aquatic Environments, France. Retrieved from http://www.onema.fr/IMG/EV/publication/ICE/CPA-ICE-Uk.pdf.

Raynal, S., Chatellier, L., Courret, D., Larinier, M., \& David L. (2013). An experimental study on fish-friendly trashracks - Part 2. Angled trashracks. Journal of Hydraulic Research, 51(1), 67-75.

Schuler, V. J., \& Larson, L. L. (1975). Improved fish protection at intake systems. J. Environ. Eng. Div., ASCE 101(6), 897-910.

Shepherd, D., Katopodis, C., \& Rajaratnam, N. (2007). An experimental study of louvers for fish diversion. Canadian Journal of Civil Engineering, 34(6), 770-776.

Taft, E. P., Hofmann, P., Eisle, P. J., \& Horst, T. (1976). An experimental approach to the design of systems for alleviating fish impingement at existing and proposed power plant intake structures. Third Natl. Workshop Entrainment and Impingement, Ecological Analysts, Inc., Melville, N. Y., 343-365. 
Zimmermann, J. (1969). Widerstand schräg angeströmter Rechengitter [Resistance of obliquely approached rack grids]. Theodor-Rehbock-Flußbaulaboratorium, Heft 157. Universität Fridericiana, Karlsruhe, Germany (in German). 


\section{List of tables}

Table 1 Hydraulic and rack parameters for the 1:2 scale model experiments and the corresponding prototype scale values 


\section{List of figures}

Figure 1 Detailed geometric view of (a) louvre, angled bar rack and Modified angled Bar Rack (MBR), (b) flume set up of FGS, (c) top view of cross-sectional bar shapes, (d) side view of geometric parameters for the physical model investigation on louvres, angled bar racks and MBRs; adapted from Albayrak et al. (2017)

Figure 2 Schematic 3D view of the test flume with (1) honeycomb flow straightener, (2) 2D traverse system with ultrasonic distance sensor and ADV, (3) CBR, (4) PVC wall for channel width reduction, (5) flap gate

Figure 3 Geometric and hydraulic rack parameters (a) flume top view, (b) top view of crosssectional bar shapes with prototype dimensions, and (c) side view of the CBR with overlays

Figure 4 Basic head loss coefficient $\xi_{R}$ versus (a) $\sigma$, (b) $\beta$ and (c) $\alpha$ for CBR configurations without overlay

Figure 5 Rack head loss and downstream flow field of CBR with (a) $\alpha=45^{\circ}, \beta=45^{\circ}$ and $\sigma=$ 0.17 , and (b) $\alpha=45^{\circ}, \beta=90^{\circ}$ and $\sigma=0.17$; view against flow direction

Figure 6 Ratio of computed MBR head loss coefficients $\xi_{R, p}$ using Eqs. (3) and (4) to measured CBR head loss coefficients $\xi_{R, m}$ versus $\sigma$ with an average ratio of 4.2

Figure 7 Head loss factor of bar depth $C_{L}$ versus $\sigma$ for (a) $\beta=45^{\circ}$ and (b) $\beta=90^{\circ}$ including the best fit according to Eq. (6) for $\alpha=30^{\circ}(--)$ and $\alpha=45^{\circ}(-)$

Figure 8 Measured overlay head loss coefficient $C_{V, i}$ versus $V_{i}$ for top, top \& bottom and bottom overlays for (a) $\alpha=45^{\circ}, \beta=90^{\circ}$, (b) $\alpha=30^{\circ}, \beta=90^{\circ}$ and (c) $\alpha=15^{\circ}, \beta=90^{\circ}$

Figure $9 K_{V, 1}$ versus $V /(1-V)$ for $\sigma=0.17,0.08$ and $0.04, \alpha=45^{\circ}, 30^{\circ}, 15^{\circ}, \beta=45^{\circ}, 90^{\circ}$ according to Eq. (8) and experimental data for top overlay

Figure 10 Comparison of (a) measured head loss coefficients $\xi_{R, m}$ with corresponding prediction $\xi_{R, p}$ for all rack configurations (b) PE versus $\xi_{R, p}$

Figure 11 (a) Comparison of predicted $\xi_{R}$ values for trash racks and different FGSs namely HBR, MBR, and CBR with a rack angle $\alpha=30^{\circ}$ (b) Overview of the results with selection of important rack configurations: MBR and CBR with $\alpha=15^{\circ}, 30^{\circ} \& 45^{\circ}, \beta=45^{\circ}, \sigma=0.17$ and $\varepsilon=$ 1 and HBR with $\alpha=30^{\circ} \& 45^{\circ}$, blockage ratio $P=0.33(s=20 \mathrm{~mm})$ and $\varepsilon=1$ 
Table 1 Hydraulic and rack parameters for the 1:2 scale model experiments and the corresponding prototype scale values

\begin{tabular}{llll}
\hline Parameter & Model scale 1:2 & Prototype scale 1:1 & Unit \\
\hline$U_{o}$ & $\sim 0.50$ & $\sim 0.71$ & $\left(\mathrm{~m} \mathrm{~s}^{-1}\right)$ \\
$h_{o}$ & $\sim 0.40$ & $\sim 0.80$ & $(\mathrm{~m})$ \\
$w_{c h}$ & 0.5 & 1.0 & $(\mathrm{~m})$ \\
$\mathrm{R}_{b}\left(\times 10^{3}\right)$ & $\sim 2.50$ & $\sim 7.06$ & $(-)$ \\
$\mathrm{R}\left(\times 10^{5}\right)$ & $\sim 3.07$ & $\sim 8.69$ & $(-)$ \\
$\mathrm{F}$ & $\sim 0.25$ & $\sim 0.25$ & $(-)$ \\
$\alpha$ & $15,30,45$ & $15,30,45$ & $\left({ }^{\circ}\right)$ \\
$\beta$ & 45,90 & 45,90 & $\left({ }^{\circ}\right)$ \\
$s$ & $0.025,0.055,0.115$ & $0.05,0.11,0.23$ & $(\mathrm{~m})$ \\
$t$ & 0.005 & 0.01 & $(\mathrm{~m})$ \\
$d$ & $0.035,0.05,0.0625$ & $0.07,0.10,0.125$ & $(\mathrm{~m})$ \\
$h_{T o}$ or $h_{B o}$ & $(0.10,0.15,0.25) h_{o}$ & $(0.10,0.15,0.25) h_{o}$ & $(\mathrm{~m})$ \\
$h_{v}$ & $(0.20,0.30) h_{o}$ & $(0.20,0.30) h_{o}$ & $(\mathrm{~m})$ \\
\hline
\end{tabular}


(a)

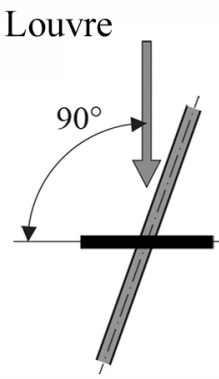

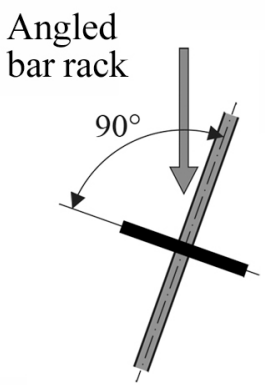

Modified angled bar rack

(b)

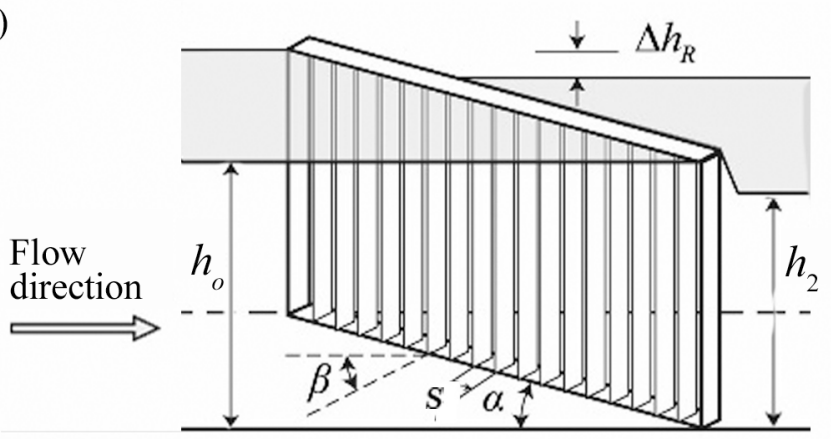

(c)
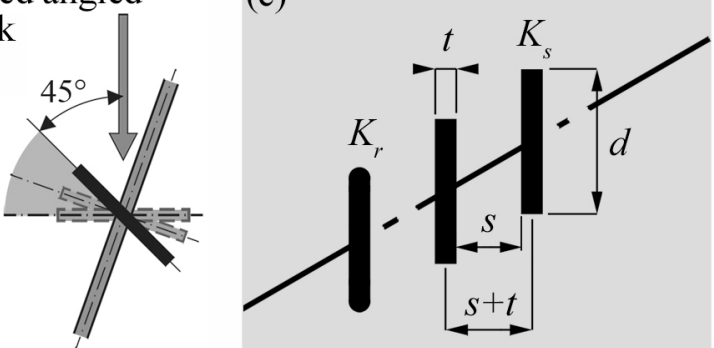

(d)
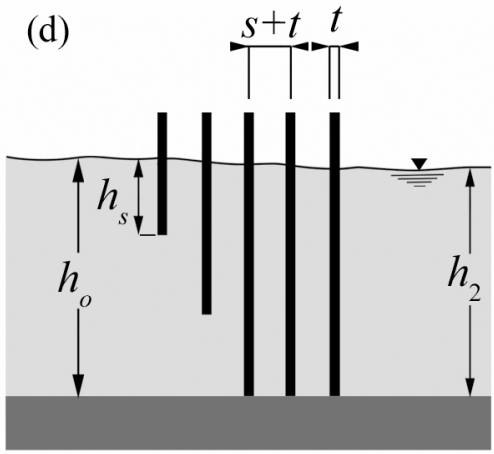

Figure 1 Detailed geometric view of (a) louvre, angled bar rack and Modified angled Bar Rack (MBR), (b) flume set up of FGS, (c) top view of cross-sectional bar shapes, (d) side view of geometric parameters for the physical model investigation on louvres, angled bar racks and MBRs; adapted from Albayrak et al. (2017) 


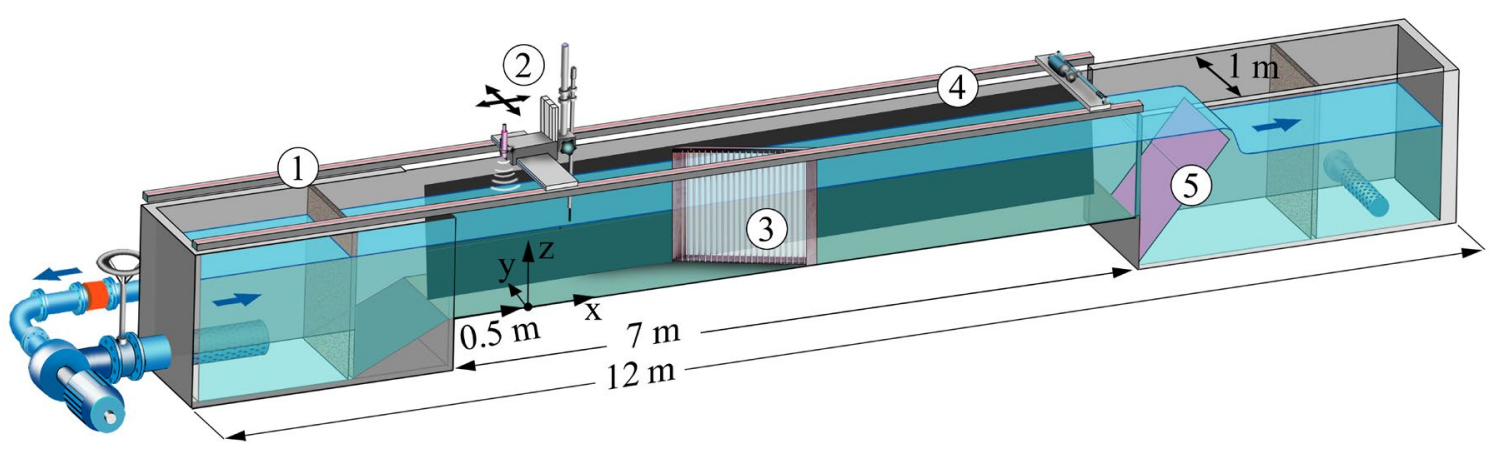

Figure 2 Schematic 3D view of the test flume with (1) honeycomb flow straightener, (2) 2D traverse system with ultrasonic distance sensor and ADV, (3) CBR, (4) PVC wall for channel width reduction, (5) flap gate 

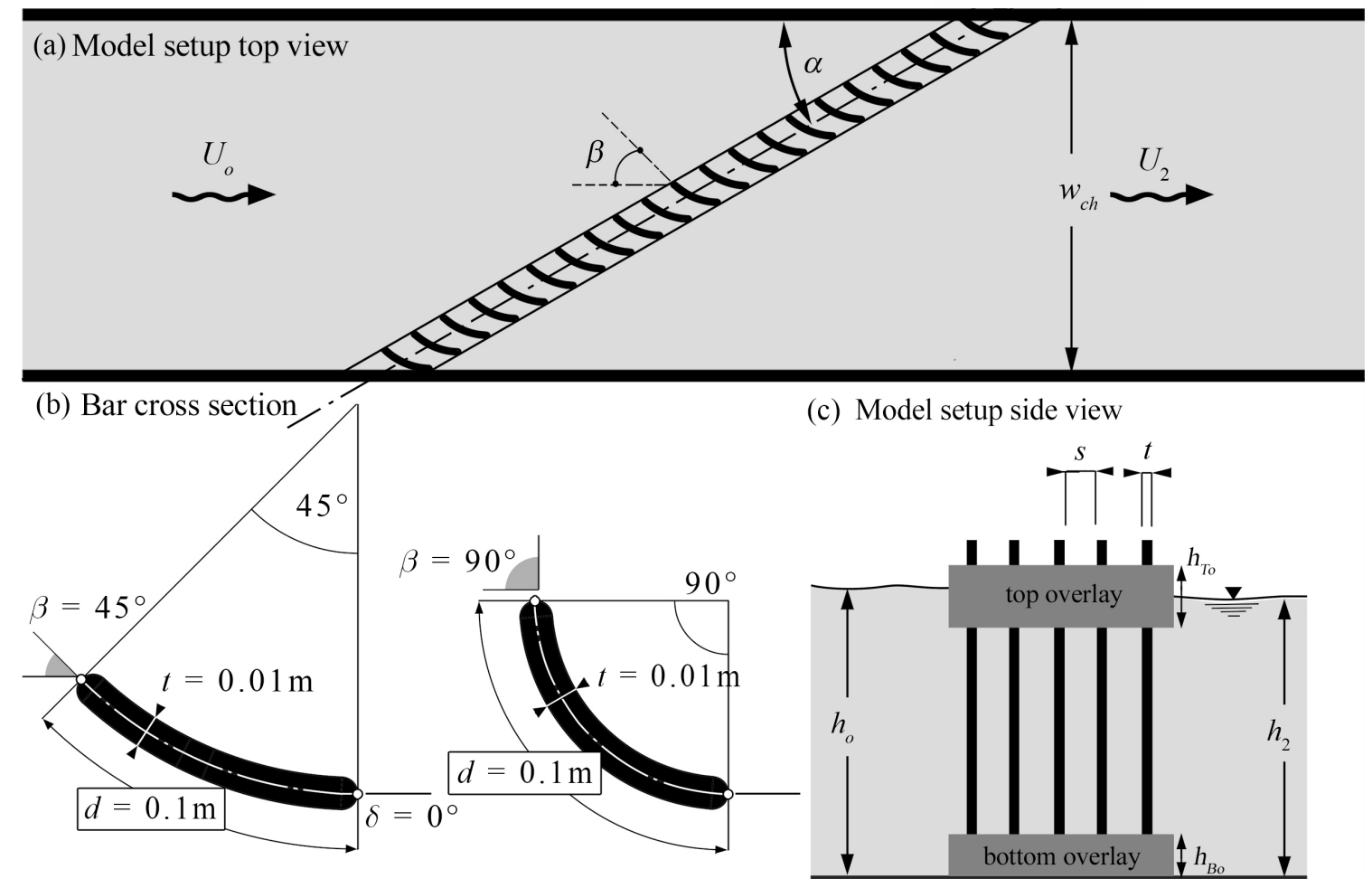

Figure 3 Geometric and hydraulic rack parameters (a) flume top view, (b) top view of crosssectional bar shapes with prototype dimensions, and (c) side view of the CBR with overlays 

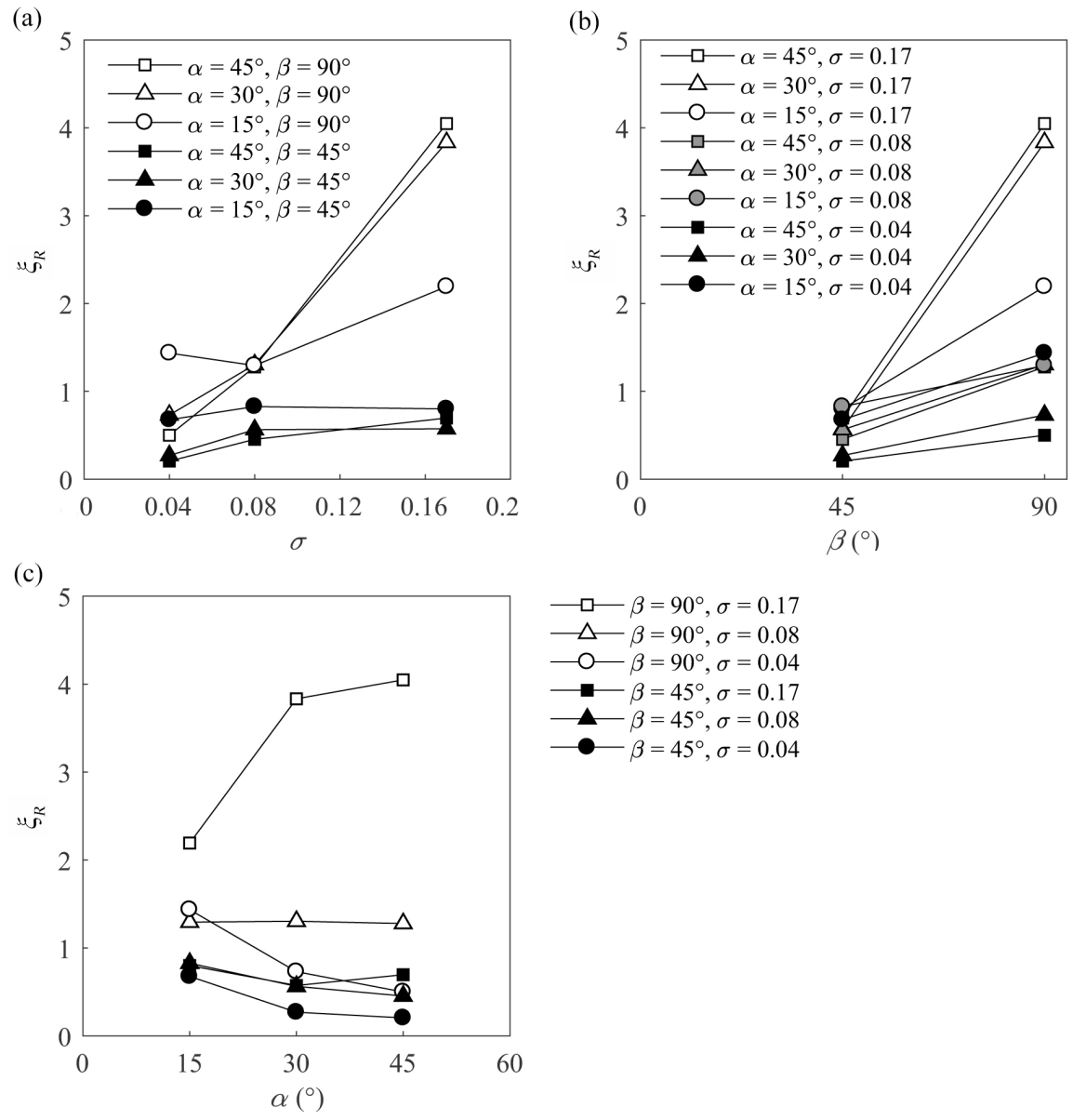

Figure 4 Basic head loss coefficient $\xi_{R}$ versus (a) $\sigma$, (b) $\beta$ and (c) $\alpha$ for CBR configurations without overlay 


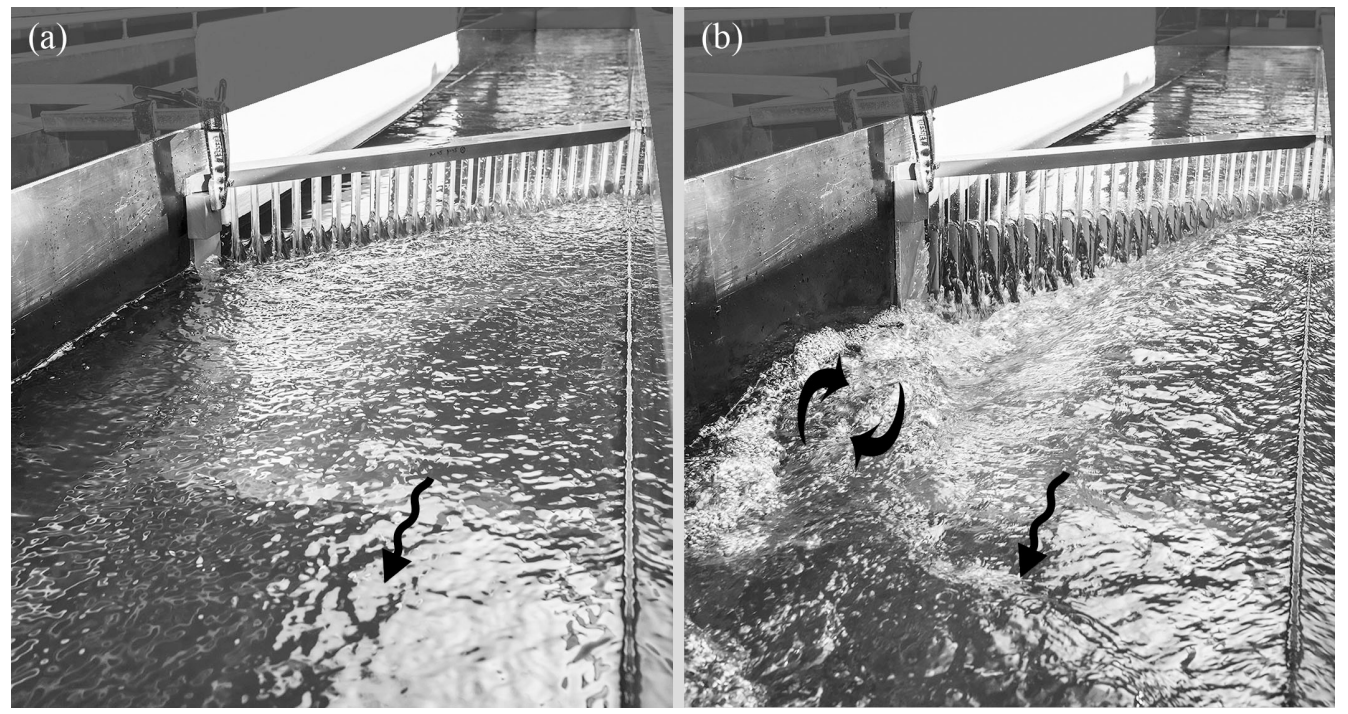

Figure 5 Rack head loss and downstream flow field of CBR with (a) $\alpha=45^{\circ}, \beta=45^{\circ}$ and $\sigma=$ 0.17 , and (b) $\alpha=45^{\circ}, \beta=90^{\circ}$ and $\sigma=0.17$; view against flow direction 


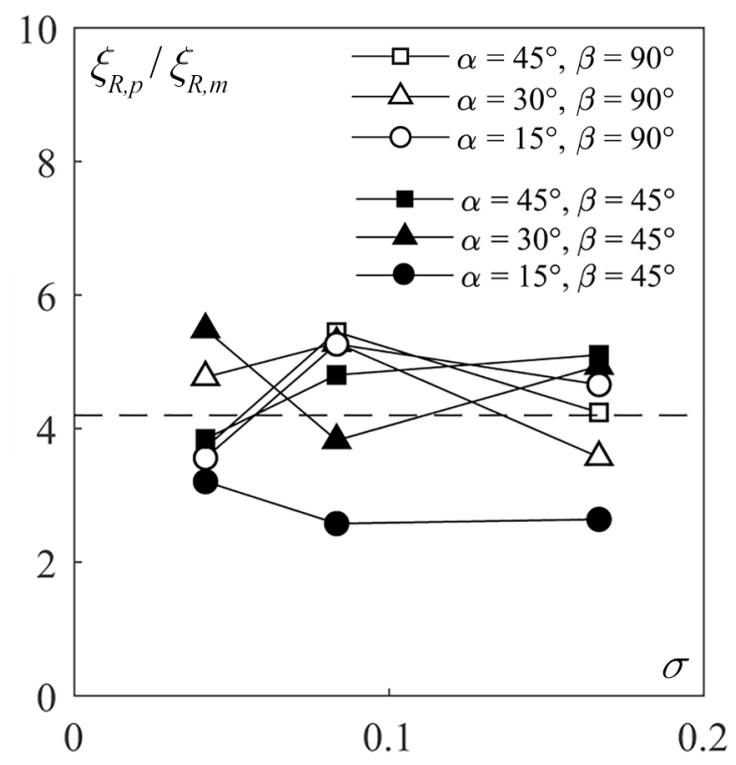

Figure 6 Ratio of computed MBR head loss coefficients $\xi_{R, p}$ using Eqs. (3) and (4) to measured CBR head loss coefficients $\xi_{R, m}$ versus $\sigma$ with an average ratio of 4.2 
(a)

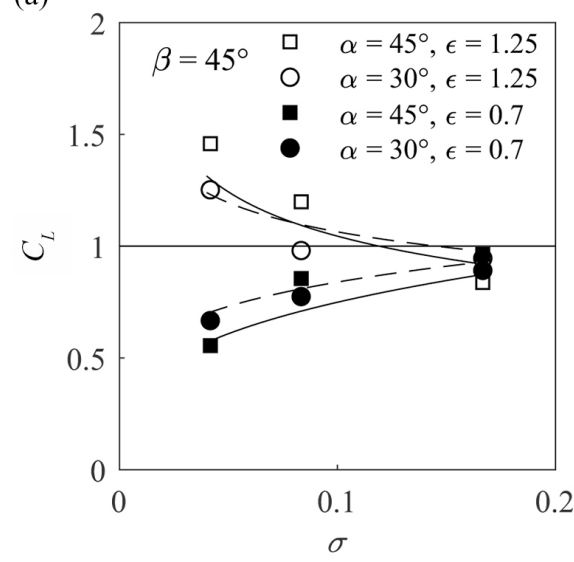

(b)

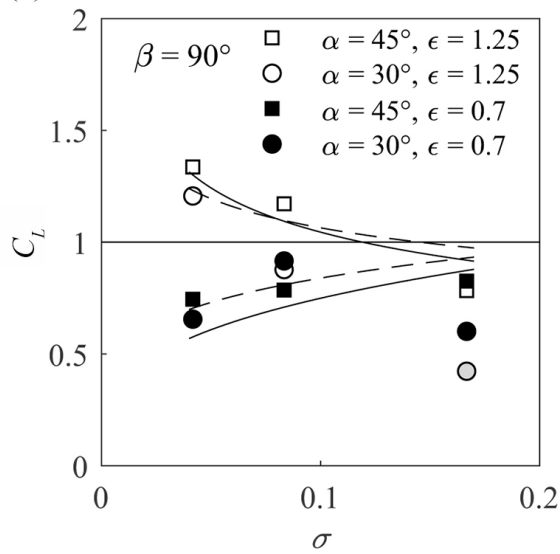

Figure 7 Head loss factor of bar depth $C_{L}$ versus $\sigma$ for (a) $\beta=45^{\circ}$ and (b) $\beta=90^{\circ}$ including the best fit according to Eq. (6) for $\alpha=30^{\circ}$ (---) and $\alpha=45^{\circ}(-)$ 


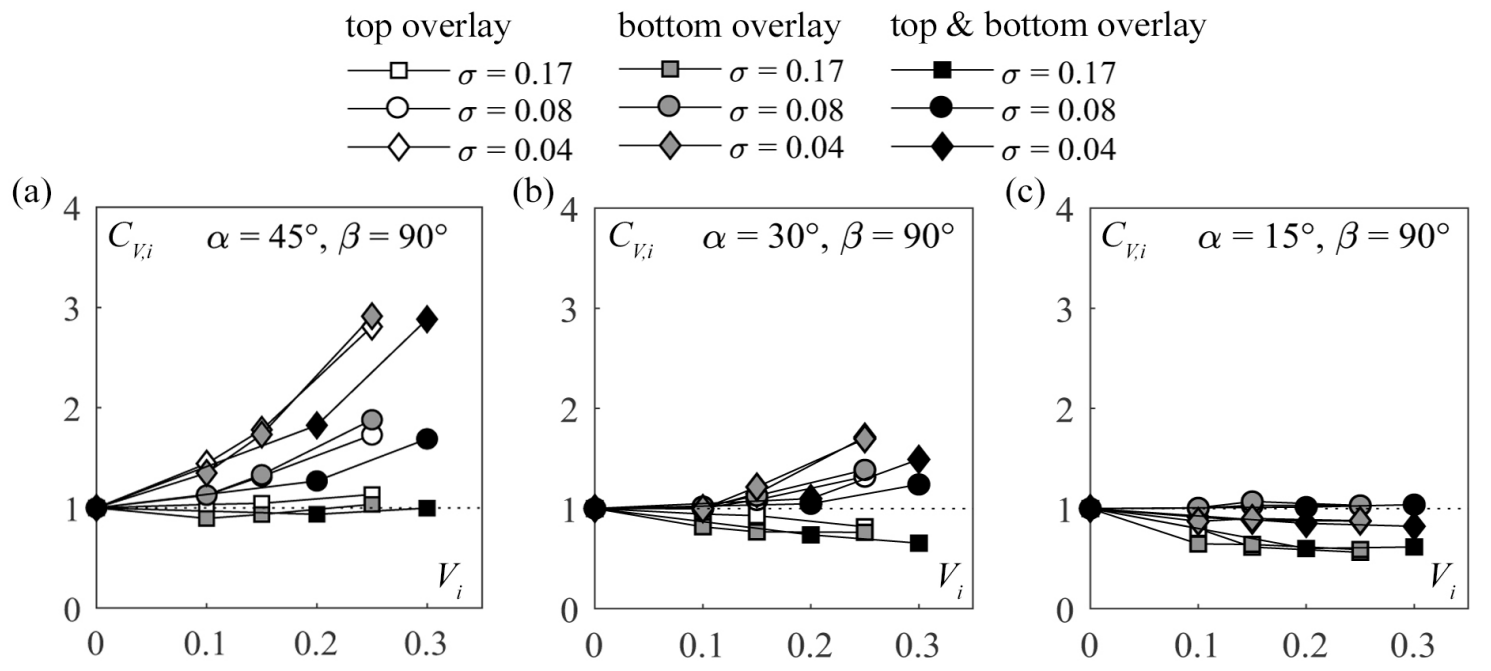

Figure 8 Measured overlay head loss coefficient $C_{V, i}$ versus $V_{i}$ for top, top $\&$ bottom and bottom overlays for (a) $\alpha=45^{\circ}, \beta=90^{\circ}$, (b) $\alpha=30^{\circ}, \beta=90^{\circ}$ and (c) $\alpha=15^{\circ}, \beta=90^{\circ}$ 

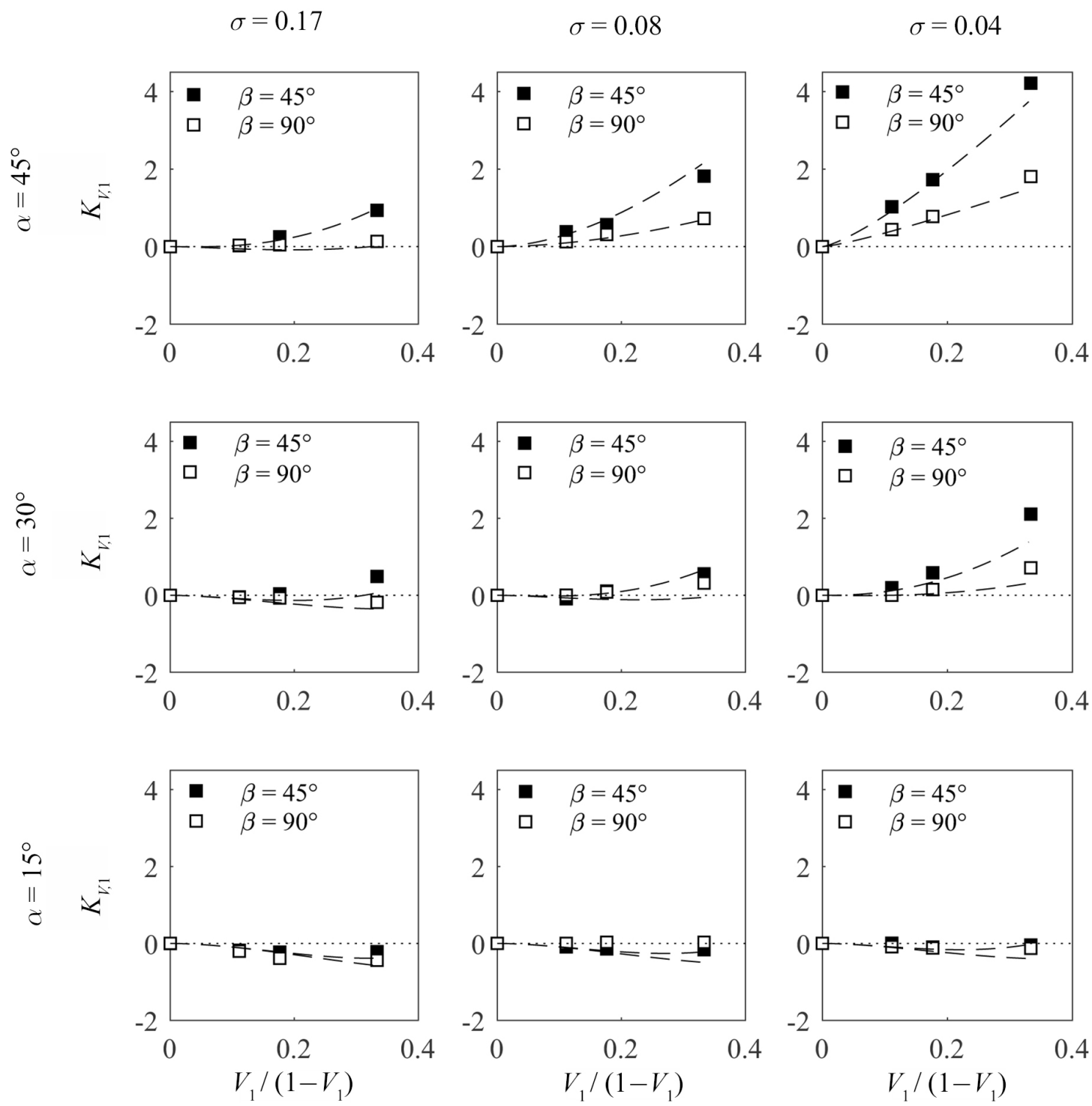

Figure $9 K_{V, 1}$ versus $V /(1-V)$ for $\sigma=0.17,0.08$ and $0.04, \alpha=45^{\circ}, 30^{\circ}, 15^{\circ}, \beta=45^{\circ}, 90^{\circ}$ according to Eq. (8) and experimental data for top overlay 

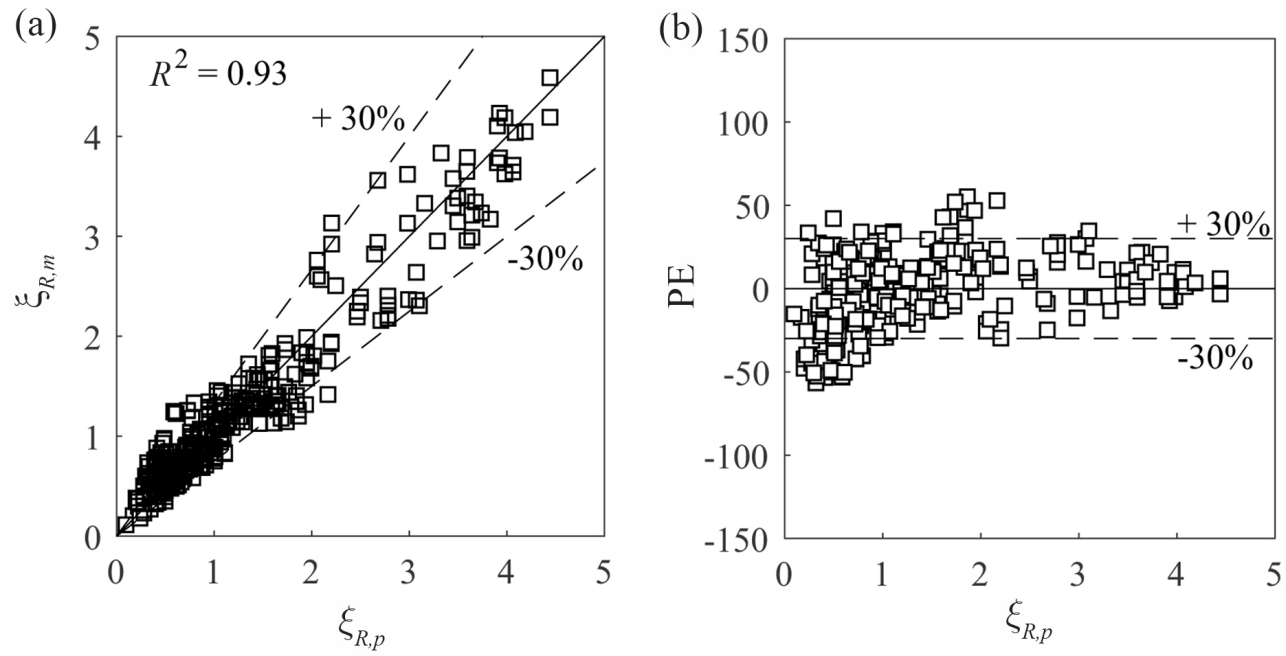

Figure 10 Comparison of (a) measured head loss coefficients $\xi_{R, m}$ with corresponding prediction $\xi_{R, p}$ for all rack configurations (b) PE versus $\xi_{R, p}$ 
(a)

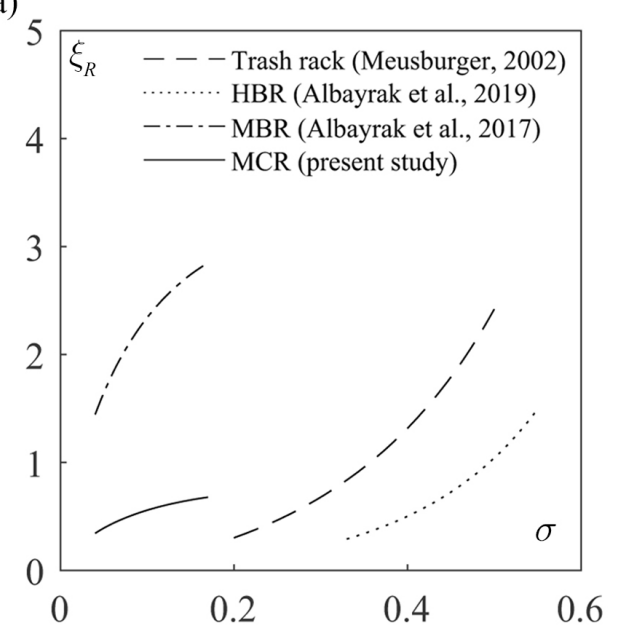

(b)

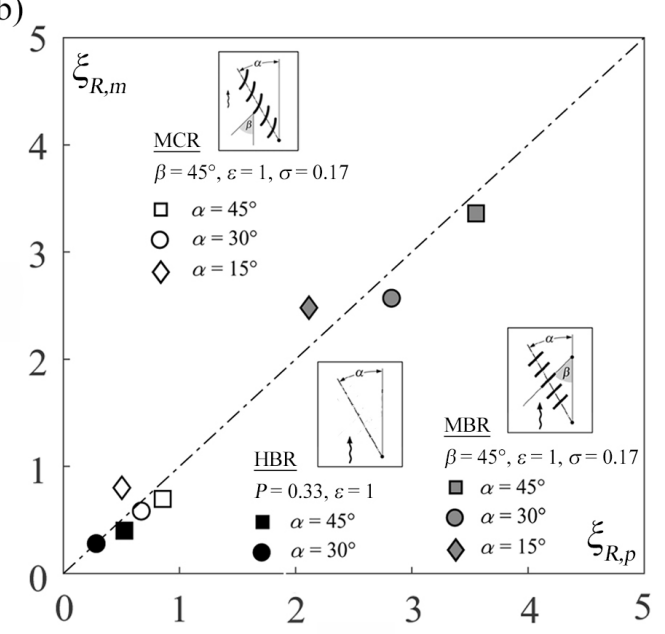

Figure 11 (a) Comparison of predicted $\xi_{R}$ values for trash racks and different FGSs namely HBR, MBR, and CBR with a rack angle $\alpha=30^{\circ}$ (b) Overview of the results with selection of important rack configurations: MBR and CBR with $\alpha=15^{\circ}, 30^{\circ} \& 45^{\circ}, \beta=45^{\circ}, \sigma=0.17$ and $\varepsilon=$ 1 and HBR with $\alpha=30^{\circ} \& 45^{\circ}$, blockage ratio $P=0.33(s=20 \mathrm{~mm})$ and $\varepsilon=1$ 